\title{
The effects of financial incentives on diabetes prevention program attendance and weight loss among low-income patients: the We Can Prevent Diabetes cluster-randomized controlled trial
}

\author{
Jay R. Desai ${ }^{1,2^{*}}$ (D) Gabriela Vazquez-Benitez ${ }^{1}$, Gretchen Taylor², Sara Johnson², Julie Anderson², Joyce E. Garrett ${ }^{3}$, \\ Todd Gilmer ${ }^{4}$, Houa Vue-Her ${ }^{2}$, Sarah Rinn ${ }^{3}$, Katelyn Engel ${ }^{5}$, Jeff Schiff ${ }^{3}$ and Patrick J. O'Connor ${ }^{1}$
}

\begin{abstract}
Background: Penetration and participation of real life implementation of lifestyle change programs to prevent type 2 diabetes has been challenging. This is particularly so among low income individuals in the United States. The purpose of this study is to examine the effectiveness of financial incentives on attendance and weight loss among Medicaid beneficiaries participating in the 12-month Diabetes Prevention Program (DPP).

Methods: This is a cluster-randomized controlled trial with two financial incentive study arms and an attention control study arm. Medicaid beneficiaries with prediabetes from 13 primary care clinics were randomly assigned to individually earned incentives (IND; 33 groups; $n=309$ ), a hybrid of individual- and group-earned incentives (GRP; 30 groups; $n=259$ ), and an attention control (AC; 30 groups; $n=279)$. Up to $\$ 520$ in incentives could be earned for attaining attendance and weight loss goals over 12 months. Outcomes are percent weight loss from baseline, achieving $5 \%$ weight loss from baseline, and attending $75 \%$ of core and $75 \%$ of maintenance DPP sessions. Linear mixed models were used to examine weight change and attendance rates over the 16 weeks and 12 months.

Results: The percent weight change at 16 weeks for the IND, GRP, and AC participants were similar, at $-2.6,-3.1 \%$, and $-3.4 \%$, respectively. However, participants achieving $5 \%$ weight loss in the IND, GRP, and AC groups was 21.5, $24.0 \%$ (GRP vs AC, $P<0.05$ ), and $15.2 \%$. Attendance at $75 \%$ of the DPP core sessions was significantly higher among IND $(60.8 \%, P<0.001)$ and GRP $(64.0 \%, P<0.001)$ participants than among AC $(38.6 \%)$ participants. Despite substantial attrition over time, attendance at $75 \%$ of the DPP maintenance sessions was also significantly higher among IND $(23.0 \%, P<0.001)$ and GRP $(26.1 \%, P<0.001)$ participants than among AC (11.0\%) participants.

Conclusions: Financial incentives can improve the proportion of Medicaid beneficiaries attending the 12-month DPP and achieving at least $5 \%$ weight loss.

(Continued on next page)
\end{abstract}

\footnotetext{
* Correspondence: Jay.Desai@state.mn.us

'HealthPartners Institute, Bloomington, MN, USA

${ }^{2}$ Minnesota Department of Health, 85 East 7th Place, P.O. Box 64882, St. Paul, MN 55164, USA

Full list of author information is available at the end of the article
}

(c) The Author(s). 2020 Open Access This article is licensed under a Creative Commons Attribution 4.0 International License, which permits use, sharing, adaptation, distribution and reproduction in any medium or format, as long as you give appropriate credit to the original author(s) and the source, provide a link to the Creative Commons licence, and indicate if changes were made. The images or other third party material in this article are included in the article's Creative Commons licence, unless indicated otherwise in a credit line to the material. If material is not included in the article's Creative Commons licence and your intended use is not permitted by statutory regulation or exceeds the permitted use, you will need to obtain permission directly from the copyright holder. To view a copy of this licence, visit http://creativecommons.org/licenses/by/4.0/. The Creative Commons Public Domain Dedication waiver (http://creativecommons.org/publicdomain/zero/1.0/) applies to the data made available in this article, unless otherwise stated in a credit line to the data. 
(Continued from previous page)

Trial registration: ClinicalTrials.gov NCT02422420; retrospectively registered April 21, 2015.

Keywords: Diabetes type 2 prevention, Lifestyle intervention, Financial incentives, Weight loss, Low income individuals, Medicaid

\section{Background}

An estimated 353 million adults worldwide are at high risk of developing diabetes [1]. Numerous randomized controlled diabetes prevention lifestyle interventions have demonstrated strong efficacy in delaying or reducing the onset of type 2 diabetes among high risk adults yet penetration and participation of real-world diabetes prevention programs has been limited [2-6]. In the United States this has been a particular challenge among low-income, less educated, and culturally diverse individuals [7, 8]. A metaanalysis of community-based DPP interventions and evaluation of the Centers for Disease Control and Prevention's (CDC's) National Diabetes Prevention Program (NDPP) found that program attendance and weight loss goals were much lower among black, Hispanic, and other racial/ethnic individuals compared to non-Hispanic whites $[9,10]$. This is concerning because these individuals have poverty rates two times higher than those of non-Hispanic whites and, among those in the highest poverty level, diabetes prevalence is $18 \%$ compared to $8 \%$ for those in the lowest poverty level $[11,12]$. Furthermore, low income individuals are increasingly insured through the public programs of Medicaid and Medicare, which account for $66 \%$ of the estimated $\$ 237$ billion in annual direct medical costs attributable to diabetes in the United States [13, 14].

A potential solution is the use of extrinsic incentives to promote participation and outcomes in diabetes prevention lifestyle programs. Several studies have demonstrated that prompt and frequent delivery of incentives can lead to improved healthy behaviors [15-22]. Many insurers and $90 \%$ of large employers in the United States are using such incentives to foster healthy behaviors and there is a growing body of evidence that financial incentives improve tobacco cessation, physical activity, healthy eating, and weight management [16, 18-21, 23-25]. The 35 million economically disadvantaged adult Medicaid recipients may be especially responsive to financial incentives $[21,26]$. Medicaid is a federal health care insurance program. In the United States adults at or below $138 \%$ of the federal poverty level are eligible for Medicaid. Some States, like Minnesota, have expanded insurance coverage to include adults at or below $200 \%$ of the federal poverty level. Currently, gaps remain in understanding the optimal incentive design for specific behaviors and populations, especially low income or culturally diverse populations who are not necessarily reached by corporate wellness programs.
At present, among 164 funded NDPP sites, 150 use participant incentives with 32 using financial incentives [5]. The NDPP incentive targets, how they are delivered and their effectiveness is, however, unknown. Providing incentives for DPP attendance may be a good approach considering that for every DPP session attended participants lost $0.31 \%$ of their baseline weight and, a $1 \mathrm{~kg}$ reduction in weight results in a $16 \%$ decrease in diabetes incidence [9, 27]. Providing incentives for attendance over 16 weeks was shown to be effective by VanEpps and colleagues as part of the Centers for Medicare \& Medicaid Services Medicaid Incentives to Prevent Chronic Disease (MIPCD) initiative but it did not result in differential weight loss $[28,29]$. The MIPCD was an ambitious effort to design and evaluate incentive programs that encourage smoking cessation, weight management, blood pressure and cholesterol control, optimal diabetes care management, and type 2 diabetes prevention [28].

We present findings from the We Can Prevent Diabetes (WCPD) study, also part of the MIPCD initiative [30]. The study was conducted among Minnesota Medicaid beneficiaries with prediabetes who were recruited from their primary care clinics. Two financial incentives structures were designed to offer immediate incentives for DPP attendance and weight loss over a 12 month period [30]. Our incentive design, patient population, recruitment process, and study duration differ from prior studies, thus adding to the current literature. We hypothesized that participants receiving financial incentives would improve DPP attendance and weight loss compared with participants not receiving incentives.

\section{Methods \\ Study design}

We conducted the three-arm, pragmatic clusterrandomized controlled WCPD study from January 2013 to December 2015 [30]. We compared Medicaid beneficiaries receiving the 12-month DPP for free but with no incentives for participation or weight loss (attention control; AC) with beneficiaries earning financial incentives based on their individual participation and weight loss (IND) and with beneficiaries earning incentives based on a hybrid of individual and group participation and weight loss (GRP). The WPCD study adheres to the CONSORT guidelines (see additional file). The study was approved by institutional review boards at the Minnesota Department 
of Health (primary), the Minnesota Department of $\mathrm{Hu}$ man Services, the University of Minnesota (on behalf of the University of Minnesota Physicians health system), HealthPartners, HealthEast, and Hennipin County Medical Center.

\section{Study participants and setting}

Minnesota adults enrolled in Medical Assistance or MinnesotaCare (i.e., Medicaid) were identified, recruited, consented, and enrolled by clinic staff at 13 primary care clinic systems in the Minneapolis-St. Paul metropolitan area [30]. These clinics serve a culturally diverse, lowincome population, including Hmong, Somali, Karen, and Latino immigrants. Participants were recruited through clinic visits, electronic medical record review with telephone outreach, and community-based outreach.

Eligible participants had to: a) be currently enrolled in Medicaid; b) be 18 to 74 years old; c) have a body mass index $\geq 25 \mathrm{~kg} / \mathrm{m}^{2}\left(\geq 22 \mathrm{~kg} / \mathrm{m}^{2}\right.$ for those of Asian descent); and d) have prediabetes or a history of gestational diabetes mellitus (GDM). Prediabetes status was classified as: a) at least one elevated blood glucose reading within 18 months of enrollment (fasting plasma glucose 5.6$6.9 \mathrm{mmol} / \mathrm{L}$ [100-125 mg/dl]; impaired glucose tolerance $7.8-11.0 \mathrm{mmol} / \mathrm{L} \quad[140-199 \mathrm{mg} / \mathrm{dl}]$; or $\mathrm{HbA} 1 \mathrm{c} 39-46$ $\mathrm{mmol} / \mathrm{mol}[5.7-6.4 \%]$ ); or b) at least one outpatient visit with a diagnosis code indicating abnormal glucose levels (ICD-9-CM 790.21, 790.22, or 790.29). Previous GDM was determined by: a) at least one outpatient or inpatient ICD-9-CM 648.8x; b) any mention of GDM in the participants' medical notes; or c) participant selfreport of GDM [30]. Additional exclusion criteria were reported elsewhere [30].

\section{Randomization and interventions}

Participants were assigned to a DPP group based on their preferred day, time, and location [30]. Groups were randomly assigned to a study arm $24 \mathrm{~h}$ before their first DPP core session using a computer-generated randomization sequence prepared by the study statistician. DPP lifestyle coaches accessed the group assignment and informed participants of their assignment at the first DPP core session.

All participants received, free of charge, the 12-month group-delivered DPP, based on the CDC NDPP standardized DPP curriculum [31]. The DPP core program consists of 16 weekly one-hour sessions. The DPP maintenance program consists of eight one-hour monthly "booster" meetings tailored to the needs of the DPP group. While participants remained in their randomized groups during the first 16 weeks, pragmatic delivery of the maintenance sessions allowed combining some participants into the same maintenance sessions. These participants retained their original incentive structures and were analyzed as such.
The DPP was delivered by YMCA lifestyle coaches [30]. During the study's last year, trained primary care clinic staff also led 21 DPP groups but with maintenance sessions modified to every 2 weeks for 4 months. For accessibility, primary care clinics identified locations best suited to their patients for delivery of the DPP sessions. These were either on-site or at a nearby community center. When possible, native-speaking DPP lifestyle coaches or interpreters were used for non-English-speaking participants.

All participants received $\$ 25$ for attending one of the first three group sessions as well as materials to support lifestyle change (i.e., measuring cups, food scale, transportation, childcare, and free access to facilities for physical activity). The IND and GRP participants could earn up to $\$ 520$ [30]. IND participants received financial incentives for each session attended, for attending at least $75 \%$ of DPP core sessions, attending at least $75 \%$ of DPP maintenance sessions, and achieving 5, 7, and 10\% weight loss during the core period and $5,7 \%$, or $10 \%$ weight loss by the end of the maintenance period [30]. GRP participants earned a financial incentive each time they attended a DPP session or achieved 5\% weight loss during the core or maintenance periods. If their entire DPP group achieved $75 \%$ core session attendance, $75 \%$ maintenance session attendance, or $7 \%$ or $10 \%$ weight loss during the core period or by the end of the maintenance period, all members of that group received the financial incentive [30]. The detailed incentive structures are described elsewhere [30]. Weight loss targets were based on the NDPP requirements (5\%), original DPP findings (7\%), and a stretch goal (10\%). If a participant dropped out due to loss of Medicaid eligibility (or other reasons described elsewhere), GRP incentives were based on the remaining DPP group participants [30]. Attending a make-up session counted as a regular session. Financial incentives were received on a reloadable debit card issued to all participants and automatically loaded when incentive goals were attained [30].

\section{Data collection}

The lifestyle coaches collected participant attendance, weight, and weekly food and physical activity logs at each DPP core and maintenance session. Weight was obtained at the beginning of each session on a portable digital scale. Data were entered into the MyNetico system within $48 \mathrm{~h}$ of the session and automatically triggered the disbursement of earned incentives [30]. Clinic staff retrieved participant vital signs, laboratory data, and smoking status from their electronic medical records systems for baseline and 12-month follow-up. Medicaid claims data were used to determine prior cardiovascular disease (ICD-9-CM 410-414, 420, 421, 423-427, 429438, 440-444, 447, 451-453, 557, 785, v42, v45, V53) 
and mental health conditions (ICD-9-CM 295-298, 300, $301,309,311)$. Participants received a $\$ 25$ reimbursement for the 12-month follow-up visit.

\section{Outcomes}

Our primary outcomes were mean weight change over the 16 core sessions and the 12-month DPP period. We also evaluated the proportion of participants who achieved 5, 7, and 10\% weight loss at any core session and at their last attended maintenance session. Attendance outcomes included the mean number of core, maintenance, and total sessions attended; the percent of participants who attended 12 core sessions; and the percent who attended six maintenance sessions. We also reported percent completion of the food and physical activity logs, and the percent of participants reporting 150 min of activity per week [30].

\section{Statistical analysis}

All analyses were based on a participants original assigned study arm. We used the chi-square and F-test to compare baseline differences between the study arms. Linear mixed models were used to examine weight change over the 16 weeks and 12 months for participants with two or more weight measurements within each time frame. To evaluate the effect of the financial incentives on weight change, pairwise contrasts between GRP and $\mathrm{AC}$ and between IND and $\mathrm{AC}$ were computed. We also examined contrasts between GRP and IND. The models included repeated weight measurements as the outcome variable; time (weeks from first measurement), incentive arm, a time-arm indicator, and baseline weight as fixed effects and random intercept and slope for groups, with an autoregressive AR (1) structure for the error term [30]. Weights were log transformed and then back-transformed to their original scale for comparison of study arms. We also conducted sensitivity analyses, accounting for weight trajectory outliers or over influential patterns.

We modeled attendance rates for DPP groups using a generalized linear model with binomial distribution and logit link with the same parametrization of the fixed effects [30]. A compound symmetry covariance for the error term was used to account for the nested structure of the data. For mean number of sessions attended, we used a linear mixed model, and for weight loss and attendance goals, we used a generalized linear model. Linear mixed models adequately handle missing data under the assumption of missing at random. A similar approach was used to examine completion of physical activity and food logs and self-reported physical activity during the first 16 weeks. All analyses were evaluated at a 0.05 significance level and conducted using SAS version 9.3 (SAS Institute, Inc., USA).

\section{Power analysis}

A priori power calculations were estimated based on weight change and considered the randomization and delivery at the group level. Based on prior DPP studies, we estimated that IND and GRP participants would lose $6.8 \mathrm{~kg}(15 \mathrm{lbs})$ and $9.1 \mathrm{~kg}(20 \mathrm{lbs})$, respectively, or about $0.45 \mathrm{~kg}(1 \mathrm{lb})$ per week throughout the DPP Core Sessions. With $80 \%$ power, $\alpha_{2}=0.05$ (two-tailed test), an intraclass correlation coefficient (ICC) of 0.01 , and a weight standard deviation (SD) of $19.3 \mathrm{~kg}$ (42.5 lbs), we expected to detect an effect size of $0.2(3.9 \mathrm{~kg} ; 8.5 \mathrm{lbs})$ between the incentive arms and the AC arm, with 44 groups of 10 participants per group [30].

\section{Results}

From January 1, 2013 through April 15, 2016, the 13 WCPD primary care clinic systems identified 2871 potential participants, reaching $72 \%$ and enrolling and consenting $55.7 \%$ of those contacted $(n=1154)$ [30]. Of these, 43 participants were never assigned to a randomized class and 264 participants never attended a DPP session, with no significant differences between the study arms [30]. Our analyses included the remaining 847 participants who enrolled and attended at least one DPP session (73.4\%). Ninety-three groups were started (IND = $33, \mathrm{GRP}=30, \mathrm{AC}=30$ ) with, on average, nine participants per group.

Baseline characteristics of participants are detailed in Table 1. Participants were racially and ethnically diverse. Only $17 \%$ were White while $64 \%$ were African American. However, a large proportion of African Americans were Somali immigrants and whose primary language was Somali. Almost $54 \%$ had a BMI $\geq 35 \mathrm{~kg} / \mathrm{m}^{2}$. Less than $15 \%$ had more than a high school education and $40 \%$ had evidence of a prior mental health condition.

Weight Change Outcomes: Based on planned analyses, at 16 weeks the mean percent weight change was similar for the three study arms (IND $=-2.6 \%(95 \% \mathrm{CI}-3.1$, $2.0) ; \quad \mathrm{GRP}=-3.1 \% \quad(95 \% \mathrm{CI}: \quad-3.7,-2.4) ; \quad \mathrm{AC}=-3.4 \%$ (95\%CI: - 9.2, 4.9)) (Table 2). At 12 months, mean percent weight changes for IND, GRP, and AC participants were $-3.7 \%$ (95\%CI: - 5.7,-1.6), - 4.4\% (95\%CI: - 6.5,2.2 ), and $-7.1 \%(95 \% \mathrm{CI}:-9.2,4.9)$ and non-significant. However, these results reflect the differential attrition rates across groups, and thus the number of participants contributing with data in the maintenance phase: 142 (IND), 122 (GRP), and 71 (AC) participants with two or more weight measurements from week 17 to week 52 .

During DPP core sessions, the $5 \%$ weight loss goal was met by $15.2 \%$ of AC, $21.5 \%$ of IND, and $24.0 \%$ of GRP $(P<0.05)$ participants (Table 3$)$. Significantly more GRP participants also attained $7 \%$ weight loss than did AC participants. At 12 months, significantly more IND $(20.3 \%, P<0.05)$ and GRP $(21.5 \%, P<0.05)$ participants 
Table 1 Baseline characteristics of the We Can Prevent Diabetes study subjects attending at least one Diabetes Prevention Program session, by study arm ( $n=847$; IND Individual; GRP Group/Individual; AC Attention Control)

\begin{tabular}{|c|c|c|c|}
\hline Characteristics & $\begin{array}{l}\text { IND } \\
(N=33 ; n=309)\end{array}$ & $\begin{array}{l}\text { GRP } \\
(N=30 ; n=259)\end{array}$ & $\begin{array}{l}\mathrm{AC} \\
(N=30 ; n=279)\end{array}$ \\
\hline \multicolumn{4}{|l|}{ Glucose Entry Criteria (\%) } \\
\hline $\begin{array}{l}\mathrm{HbA} 1 \mathrm{c} 39-46 \mathrm{mmol} / \mathrm{mol} \\
(5.7-6.4 \%)\end{array}$ & 62.5 & 56.8 & 60.9 \\
\hline Fasting plasma glucose $5.6-6.9$ mmol/L (100-125 mg/dl) & 26.2 & 26.9 & 29.0 \\
\hline Impaired glucose tolerance: $7.8-11.0 \mathrm{mmol} / \mathrm{L}(140-199 \mathrm{mg} / \mathrm{dL})$ & 0.3 & 0 & 0.4 \\
\hline Abnormal glucose diagnosis code (ICD-9790.2x) & 8.7 & 8.5 & 7.5 \\
\hline Self-report history of gestational diabetes & 1.3 & 6.6 & 1.4 \\
\hline None documented & 0.3 & 1.9 & 0.7 \\
\hline Mean baseline HbA1c (mmol/mol; SD) & $\begin{array}{l}40(2) \\
(5.8 \%(0.3))\end{array}$ & $\begin{array}{l}40(3) \\
(5.8 \%(0.4))\end{array}$ & $\begin{array}{l}40(2) \\
(5.8 \%(0.3))\end{array}$ \\
\hline $\begin{array}{l}\text { Diabetes diagnosis code } \\
\text { (ICD-9250.xx) }\end{array}$ & 9.7 & 10.8 & 7.2 \\
\hline Baseline weight & $\begin{array}{l}96.4 \mathrm{~kg} \\
(212.5 \mathrm{lb})\end{array}$ & $\begin{array}{l}97.3 \mathrm{~kg} \\
(214.5 \mathrm{lb})\end{array}$ & $\begin{array}{l}97.1 \mathrm{~kg} \\
(214.0 \mathrm{lb})\end{array}$ \\
\hline Mean baseline body mass index $\left(\mathrm{kg} / \mathrm{m}^{2}, \mathrm{SD}\right)$ & $35.6(8.1)$ & $37.6(8.6)$ & $36.6(7.8)$ \\
\hline Female (\%) & 70.9 & 72.6 & 70.2 \\
\hline Mean Age (years, SD) & $48.6(12.2)$ & $47.4(11.9)$ & $48.9(11.6)$ \\
\hline \multicolumn{4}{|l|}{ Race/Ethnicity (\%) } \\
\hline White & 15.5 & 25.1 & 10.8 \\
\hline Black/African American & 70.6 & 54.0 & 64.5 \\
\hline Asian & 3.9 & 2.3 & 6.4 \\
\hline American Indian/Alaska Native & 5.2 & 10.0 & 15.4 \\
\hline Native Hawaiian/Pacific Islander & 0 & 0 & 0 \\
\hline Hispanic/Latino & 4.2 & 6.2 & 1.4 \\
\hline Other or missing & 0.6 & 2.3 & 1.4 \\
\hline \multicolumn{4}{|l|}{ Primary Language (\%) } \\
\hline English & 61.2 & 78.4 & 79.2 \\
\hline Spanish & 2.9 & 3.5 & 0.4 \\
\hline Somali & 31.7 & 15.4 & 14.3 \\
\hline Hmong & 3.6 & 0.8 & 4.7 \\
\hline Other & 0.6 & 1.9 & 1.4 \\
\hline \multicolumn{4}{|l|}{ Education Level (\%) } \\
\hline$<$ High school & 40.8 & 33.2 & 35.9 \\
\hline High school & 49.2 & 50.2 & 51.2 \\
\hline More than high school & 10.0 & 16.6 & 12.9 \\
\hline \multicolumn{4}{|l|}{ Marital Status (\%) } \\
\hline Never married & 47.6 & 47.9 & 53.4 \\
\hline Married & 19.4 & 13.1 & 11.8 \\
\hline Other & 33.0 & 39.0 & 34.8 \\
\hline Previous cardiovascular disease ${ }^{a}$ (\% Yes) & 8.7 & 12.4 & 9.0 \\
\hline Previous mental health condition ${ }^{a}$ (\% Yes) & 37.9 & 40.9 & 41.2 \\
\hline YMCA lifestyle coach & 79.3 & 86.5 & 81.7 \\
\hline Clinic-based lifestyle coach & 20.7 & 13.5 & 18.3 \\
\hline
\end{tabular}

a. Based on Medicaid claims ICD-9-CM diagnostic and procedure codes. 
Table 2 Primary outcomes in the We Can Prevent Diabetes study among participants attending at least one DPP session, by study $\operatorname{arm}(n=847 ;$ INDIndividual; GRP Group/Individual; AC Attention Control)

\begin{tabular}{|c|c|c|c|c|c|}
\hline Primary Outcomes & $\begin{array}{l}\text { IND } \\
(N=33 ; n=309)\end{array}$ & $\begin{array}{l}\text { GRP } \\
(N=30 ; n=259)\end{array}$ & $\begin{array}{l}\mathrm{AC} \\
(N=30 ; n=279)\end{array}$ & $\begin{array}{l}\text { IND vs AC } \\
\text { difference }\end{array}$ & $\begin{array}{l}\text { GRP vs AC } \\
\text { difference }\end{array}$ \\
\hline \multicolumn{6}{|l|}{ Weight Change ${ }^{\mathrm{a}, \mathrm{b}}$} \\
\hline$\%$ Weight change at 16 weeks (95\% Cl) & $\begin{array}{l}-2.6 \\
(-3.1,-2.0)\end{array}$ & $\begin{array}{l}-3.1 \\
(-3.7 .-2.4)\end{array}$ & $\begin{array}{l}-3.4 \\
(-4.0,-2.7)\end{array}$ & $0.8, P=.06$ & $0.3, P=.46$ \\
\hline$\%$ Weight change at 12 months ( $95 \% \mathrm{Cl}$ ) & $\begin{array}{l}-3.7 \\
(-5.7,-1.6)\end{array}$ & $\begin{array}{l}-4.4 \\
(-6.5,-2.2)\end{array}$ & $\begin{array}{l}-7.1 \\
(-9.2,4.9)\end{array}$ & $3.4, P=.47$ & $2.7, P=.13$ \\
\hline \multicolumn{6}{|l|}{ Attendance } \\
\hline Mean number of DPP core sessions attended $(95 \% \mathrm{Cl})$ & $\begin{array}{l}11.1 \\
(10.3,11.9)\end{array}$ & $\begin{array}{l}11.4 \\
(10.5,12.3)\end{array}$ & $\begin{array}{l}10.5 \\
(10.0,11.0)\end{array}$ & $\begin{array}{l}.58 \\
P=.0005\end{array}$ & $.94, P=.0001$ \\
\hline Mean number of ALL DPP sessions attended (95\% Cl) & $\begin{array}{l}13.6 \\
(12.4,14.8)\end{array}$ & $\begin{array}{l}14.2 \\
(12.9,15.5)\end{array}$ & $\begin{array}{l}12.7 \\
(12.0,13.4)\end{array}$ & $\begin{array}{l}.89 \\
P=.0002\end{array}$ & $1.50, P<.0001$ \\
\hline
\end{tabular}

a. Number of individuals with two or more measurements for weight change at 16 weeks and from 17 to 52 weeks: IND = 279 and $142 ; \mathrm{GRP}=231$ and $122 ; \mathrm{AC}=$ 254 and 71.

b. The intra-class correlation coefficient for weight among the DPP groups was 0.11 .

achieved the $5 \%$ weight loss than did AC participants (14\%). A greater proportion of GRP participants also achieved the $7 \%(P<0.05)$ and $10 \%$ weight loss goals $(P<0.05)$ than did AC participants (Table 3). There were no weight loss goal differences between the IND and GRP participants. Additionally, among all participants achieving at least $5 \%$ weight loss, $80 \%$ maintained the weight loss through the 12-month intervention period (data not reported).

Attendance Outcomes: Attendance rates by session declined steadily from about $90 \%$ to just over $50 \%$ at week 16 in the IND and GRP participants. Among the

Table 3 Compliance metrics in the We Can Prevent Diabetes study among participants attending at least one session, by study arm. $^{\text {a,b }}$ ( $n=847$; IND Individual; GRP Group/Individual; AC Attention Control)

\begin{tabular}{|c|c|c|c|}
\hline Compliance Measures & $\begin{array}{l}\text { IND } \\
(N=33 ; n=309)\end{array}$ & $\begin{array}{l}\text { GRP } \\
(N=30 ; n=259)\end{array}$ & $\begin{array}{l}\mathrm{AC} \\
(N=30 ; n=279)\end{array}$ \\
\hline \multicolumn{4}{|l|}{ Achieved weight loss goal at any core session } \\
\hline Met $5 \%$ weight loss goal, $\%$ & 21.5 & $24.0^{*}$ & 15.2 \\
\hline Met $7 \%$ weight loss goal, $\%$ & 8.2 & $13.4^{* *}$ & 9.3 \\
\hline Met $10 \%$ weight loss goal, $\%$ & 2.3 & 4.3 & 1.5 \\
\hline \multicolumn{4}{|l|}{ Achieve weight loss goal at any maintenance session } \\
\hline Met $5 \%$ weight loss goal, $\%$ & $20.3^{*}$ & $21.5^{*}$ & 14 \\
\hline Met $7 \%$ weight loss goal, $\%$ & 11.0 & $15.7^{*}$ & 9.7 \\
\hline Met $10 \%$ weight loss goal, $\%$ & 4.9 & $10.3^{*}$ & 5.5 \\
\hline \multicolumn{4}{|l|}{ Attendance (includes make-up sessions) } \\
\hline Attended at least 12 DPP core sessions, $\%$ & $60.8^{* * *}$ & $64.0^{* * *}$ & 38.6 \\
\hline Attended at least six DPP maintenance sessions, $\%$ & $23.0^{* * *}$ & $26.1^{* * *}$ & 11.0 \\
\hline \multicolumn{4}{|l|}{ Food and Physical Activity Logs (weeks 4-16) } \\
\hline $\begin{array}{l}\text { Mean number of sessions a participant completed } \\
\text { their weekly food log }\end{array}$ & 3.3 & $5.2^{*}$ & 3.4 \\
\hline $\begin{array}{l}\text { Mean number of sessions a participant completed } \\
\text { their weekly food log per number of sessions attended }\end{array}$ & 0.42 & $0.63^{*}$ & 0.53 \\
\hline $\begin{array}{l}\text { Mean number of sessions a participant completed } \\
\text { their weekly physical activity log }\end{array}$ & 5.0 & 5.5 & 4.5 \\
\hline $\begin{array}{l}\text { Mean number of sessions a participant completed } \\
\text { their weekly physical activity log per number of sessions attended }\end{array}$ & 0.62 & 0.67 & 0.72 \\
\hline Mean physical activity minutes per week among participants reporting logs & 164 & 213 & 177 \\
\hline Achieved at least 150 min per week, \% & 30.0 & $47.4^{*}$ & 35.6 \\
\hline
\end{tabular}

a. Comparisons are between each incentive arm and the Attention Control arm.

b. ${ }^{*} P<0.05,{ }^{* *} P<0.01,{ }^{* * *} P<0.001$ 
AC participants, attendance was just over $30 \%$ at week 16. Rate of decline was similar for IND and GRP $(P=$ 0.742 ) but were significantly lower compared to the $\mathrm{AC}$ participants (IND vs AC, $P<0.001$; GRP vs AC, $P<$ 0.001 ) (Fig. 1). Sixty-one percent of IND and $64 \%$ of the GRP participants attended at least $75 \%$ of the DPP core sessions, compared with $39 \%$ of AC participants $(P<$ 0.001 ). Attendance of at least $75 \%$ of DPP maintenance sessions was 23 and $26 \%$ for the IND and GRP participants, respectively, compared with $11 \%$ for the AC participants (Table 3).

Food and Physical Activity Monitoring: Weekly completion of food and physical activity logs was monitored in DPP core sessions 4 through 16 . In general, completion of food and physical activity logs was low with, on average, 3.3 to 5.2 sessions. This represented 42 to $63 \%$ of sessions attended, depending on the study arm. Among beneficiaries completing their physical activity log, the proportion self-reporting at least $150 \mathrm{~min}$ of physical activity per week was 30, 47, and 36\% among the IND, GRP, and AC participants, respectively (Table 3 ).

Incentives earned: A total of $\$ 116,205$ in incentives was disbursed to the 847 participants (IND $=\$ 60$, 120; $\mathrm{GRP}=\$ 49,110 ; \mathrm{AC}=\$ 6975)$. The median, lower quartile, and upper quartile of incentives earned per participant for IND participants were $\$ 215, \$ 85$, and $\$ 285$, respectively. These were $\$ 215, \$ 95$, and $\$ 270$ for GRP participants and $\$ 25$ for $\mathrm{AC}$ participants.

\section{Discussion}

In this pragmatic randomized controlled trial with Medicaid beneficiaries in the United States, we found that financial incentives substantially increased DPP participation during core sessions and modestly increased participation during maintenance sessions. All three study arms lost 2.6 to $3.4 \%$ from their baseline weight (5.5 to 7.3 lbs.) during the first 16 weeks. By 12 months, weight loss was $7.1 \%$ in the AC study arm, compared with 3.7 and $4.4 \%$ in the IND and GRP study arms; however, due to participant attrition, these differences were not significant. Thus, financial incentives did not differentially affect mean weight loss during DPP core and maintenance sessions.

Despite no differences in mean weight loss, a greater proportion of IND and GRP participants attained 5\% weight loss during the first 16 weeks and at 12 months than did AC participants. Significantly more GRP participants also achieved 7 and $10 \%$ weight loss at 12 months suggesting that group-based incentives may enhance weight loss by promoting group support or accountability. It was notable that sustained weight loss was observed among $80 \%$ of all participants who were able to achieve at least $5 \%$ weight loss. This may represent a high level of intrinsic motivation to improve healthy behaviors among these participants, potentially facilitated by extrinsic financial incentives since a greater proportion of participants in the IND and GRP groups achieved at least $5 \%$ weight loss.

Similar MIPCD DPP financial incentive interventions were implemented among Montana and New York Medicaid beneficiaries [28, 29, 32, 33]. A composite evaluation across all three studies found increased DPP

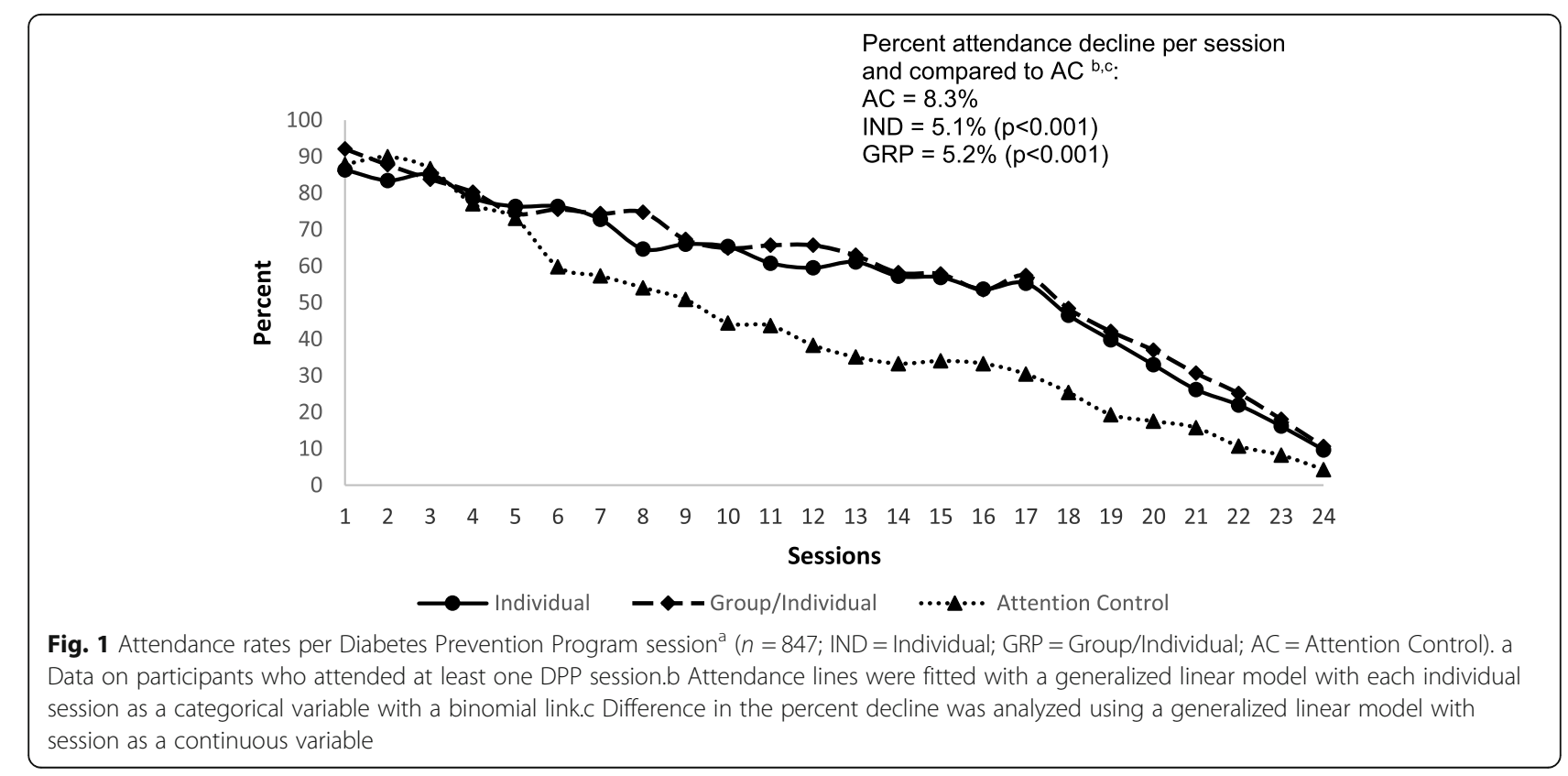


attendance in participants receiving incentives but with no significant differences in weight loss between participants with and without incentives [33]. In contrast to the WCPD, New York and Montana did not find differences in the proportion of participants achieving 5\% weight loss. In fact, in New York, 19 to $43 \%$ of participants across all study arms, including the $36 \%$ of the control group, achieved 5\% weight loss $[29,32]$. In all these studies, weight was only measured at a DPP session and thus reflects participants retained in the study over time. This is important to consider. Participant attrition at 16 weeks was almost two times higher in New York compared with WCPD, even with similar incentive structures [29]. This suggests other study design factors such as eligibility criteria, recruitment approaches, and DPP delivery may impact retention beyond the financial incentive structures and could potentially 'wash-out' incentive weight loss effects by retaining primarily participants with high initial intrinsic motivation in the treatment and control study arms.

Among Minnesota Medicaid beneficiaries, receipt of the incentives was immediate, and the GRP design may have fostered peer accountability and support. These design characteristics have proven effective in several weight loss and physical activity studies [19, 24, 34]. However, most previous studies lasted fewer than 6 months, and behavior changes were not sustained after the incentives were removed $[15,18,34]$. Longer-term (>6 months) incentive effects are likely diminished due to loss of motivation, difficulty in adhering to the behaviors, and lack of or less frequent incentives [17, 23, 3436]. We may have experienced this in the WCPD when, at 4 months, incentives changed from once a week to only once a month and attrition rates appeared to rise among the intervention arms.

The MIPCD studies used a standard-gain economic model for structuring incentives. Participants were guaranteed known financial rewards for participation, weight loss, and in Montana, completing food and physical activity logs. These are DPP leverage points within participant control. Future studies could explore other instrumental targets such as providing incentives for individually tailored step-wise improvements in healthy behaviors and outcomes. Another promising approach would be to explore incentive designs leveraging behavioral economic principles as these have demonstrated improved weight loss and physical activity compared to standard gain designs $[15,17,18,37]$. Capitalizing on a person's tendencies to expect future rewards based on past experience, desire for rapid feedback and rewards, aversion to loss, loss regret, and response to variable reinforcement may increase the effectiveness of financial incentives, particularly in low-income populations [22,
38, 39]. Currently, however, such studies in low-income or culturally diverse populations do not exist.

Participants in most DPP community-based translational studies have not been able to achieve a weight loss of $5 \%$ from baseline $[9,10,40]$. Furthermore, $25 \%$ of eligible NDPP participants did not even enroll in the program, and another $23 \%$ were lost to attrition $[9,10,41]$. We experienced similar issues, with $37 \%$ of those contacted declining to participate or never attending a DPP session after enrolling while among AC participants attending at least one DPP session, less than $40 \%$ attended 12 or more DPP core sessions, and only $11 \%$ attended 6 or more DPP maintenance sessions. Like the NDPP, the WPCD also found a $0.31 \%$ weight decrease for each attended session. But, even with the DPP provided at no cost, classes arranged for convenience (i.e., location, day, time, free childcare, and free transportation), cultural adaptations (i.e., culturally trained lifestyle coaches, interpreters, groups with culturally similar participants), and recruitment from trusted providers, sustained engagement among Medicaid beneficiaries without additional motivators like incentives was difficult [9].

Currently, eight States provide Medicaid DPP reimbursement. In the WCPD, accounting for programs costs and the incentives earned by Medicaid beneficiaries, the DPP was cost-effective and, therefore, should be more broadly considered by payers [42]. In addition, increasing organizational capacity to deliver the DPP in low-income communities is needed. This may require the CDC Diabetes Prevention Recognition Program to revisit the $5 \%$ weight loss recognition requirements; otherwise, DPP-delivery organizations serving lowincome individuals will be in danger of losing their certification and reimbursement status, exacerbating diabetes health disparities [43, 44].

Limitations: Our study has some limitations. First, participants volunteered for this study and were mostly women, reducing generalizability to all Medicaid beneficiaries and suggesting novel strategies may be needed to engage men in the NDPP. However, from a pragmatic perspective, we believe Medicaid beneficiaries who are women would be more likely to participate in similar programs. Furthermore, our participants were racially, ethnically, and culturally diverse. They did, however, cluster within the same DPP groups which enhanced DPP delivery but reduced power for the analyses because the unit of randomization was the DPP group. In addition, we had initially powered on 44 DPP groups per arm with an average of 10 participants. At the end of the study, we had 30 groups per arm with an average of nine participants per group thus limiting our power to detect significant differences. Analytically, we offset the effect of these two factors by using repeated weight measurements within participants and covariate adjustment. 
Second, our primary outcomes were assessed at DPP sessions. If a participant did not attend a session, we did not have weight information, which was problematic, especially after 16 weeks. Third, though participant characteristics were associated with lost to follow-up these were similar across study arms, even though attrition was larger in the AC group. Overall, participants lost-tofollow-up at 16 weeks were younger, African American, had Somali as their primary language, and were less educated which suggests that future studies may need to tailor their designs to better engage and support participation of these individuals. Interestingly, even though $40 \%$ of participants had evidence of a mental health condition, this did not differentially impact attrition although it may have influenced adherence and weight loss. Finally, participants and lifestyle coaches were not blinded to the study assignments. Lifestyle coaches may have been more or less engaged given the intervention assignment, but we were unable to determine this potential effect. Nonetheless, all investigators, statisticians, and data analysts were blinded to study assignments until study completion.

\section{Conclusion}

The DPP is an intensive, 12-month, structured lifestyle program designed to help participants increase physical activity, eat healthier, reduce caloric intake, lose weight, and ultimately, prevent or delay the onset of diabetes. Modifying habits established over many years is challenging-and potentially more so for Medicaid beneficiaries, who are often less educated, un- or under-employed, struggling to maintain family and housing stability, and living in obesogenic environments where food and physical activity options are limited [45]. Despite these difficulties, our study demonstrated that, with active outreach from trusted primary care providers, a culturally diverse group of Medicaid beneficiaries were interested in an intensive, structured, and free lifestyle behavior change program. However, reward-based financial incentives were needed to sustain participation and promote achievement of weight loss goals. Financial incentives may be an avenue to overcome individual, socioeconomic, and environmental barriers experienced by low-income populations in the United States and provide a model for bridging primary care health systems with community-based health programs [46]. We did find the WCPD to be cost-effective, thus, it could improve the current and future health status of a large number of Medicaid beneficiaries while mitigating future health care costs [42]. At the same time, future incentive studies need to carefully consider design factors such as individually tailored goals, targeting other outcomes such as physical functioning, and using incentive structures informed by behavioral economics to maximize participation and improvements in cardio metabolic outcomes among low-income populations that are quite heterogeneous in terms of race, ethnicity, immigration status, and culture.

\section{Key messages}

Compared to no financial incentives, financial incentives can significantly improve attendance to diabetes prevention program sessions and may increase the proportion of participants achieving the goal of at least $5 \%$ weight loss from baseline weight.

\section{Supplementary information}

Supplementary information accompanies this paper at https://doi.org/10 1186/s12889-020-09683-5.

\section{Additional file 1.}

\section{Abbreviations}

AC: Attention control group; CDC: Centers for disease control and prevention; DPP: Diabetes prevention program; GRP: Individual-group hybrid incentive group; IND: Individual incentive group; WCPD: We can prevent diabetes study; MIPCD: Medicaid incentives to prevent chronic disease initiative

\section{Acknowledgements}

We would like to thank our colleagues at the Minnesota Department of Human Services (Kathleen Vanderwall, Virginia Zawistowski, Titilope Adeniyi, Jonathan Bailey), the Minnesota Department of Health (Tamara Didion), HealthPartners Institute (Juliana Tillema, Mary Becker, Brian Martinson, Mary Van Beusekom), the Greater Twin Cities YMCA (Sheryl Grover), and the Diabetes Prevention and Control Alliance (Timothy Koehler, Thao Fiore, Patti Klugherz, Phillip Miller) for their substantial contributions in developing, implementing, and evaluating the WCPD study. We would also like to thank members of the WCPD Advisory Council for their guidance in designing the study and all the staff from participating primary care clinics: Community University Health Care Center, Crown Medical Center, Neighborhood HealthSource, HealthEast, Entira, People's Center Health Services, Westside Community Health Services, HealthPartners St. Paul Clinic, Native American Community Clinic, Open Cities, Health Center, University of Minnesota Physicians, Axis Medical Center, Hennepin County Medical Center, NorthPoint Health, and Wellness Center, Inc. Finally, and most important, we would like to thank the dedicated DPP lifestyle instructors from the YMCA of the Greater Twin Cities and participating primary care clinics. Financial Disclosure: The authors declare that they have no relevant financial interests.

\section{Authors' contributions}

JRD initiated the study, participated in its design, coordination, implementation, analyses, and writing the manuscript. GVB participated in the study design, data collection, analyses, and writing the manuscript. GT initiated the study, participated in its design, coordination, implementation, and writing the manuscript. SJ participated in the study coordination and implementation and revising the manuscript. JA participated in the study coordination and implementation, data collection, and revising the manuscript. JG participated in the study coordination, data collection, and writing the manuscript. TG participated in the study design, data collection, analyses, and writing the manuscript. HVH participated in the study coordination, implementation, and writing the manuscript. SR participated in study coordination and implementation, data collection, and writing the manuscript. KE participated in the study implementation, data collection, and writing the manuscript. JS participated in the study design, coordination, and writing the manuscript. PJO participated in the study design, analyses, and writing the manuscript. All author's have read and approved the manuscript. 


\section{Funding}

This study was supported by Funding Opportunity Number 1BCMS330901 from the Centers for Medicare \& Medicaid Services. Drs. O'Connor and Desai also received partial support from the National Institutes of Health, National Institute of Diabetes and Digestive and Kidney Diseases (NIDDK) grant P30DK092928. The funders did not contribute to study design, data collection, analyses, or interpretation of data. The contents provided are solely the responsibility of the authors and do not necessarily represent the official views of the Department of Health and Human Services or any of its agencies. The results presented have not been verified by the independent evaluation contract.

\section{Availability of data and materials}

The datasets analyzed during the current study are available from the corresponding author upon request.

\section{Ethics approval and consent to participate}

Participants provided written consent to participate in the study. The study was approved by the institutional review boards at the Minnesota Department of Health (primary), the Minnesota Department of Human Services, the University of Minnesota, HealthPartners, HealthEast, and Hennepin County Medical Center.

\section{Consent for publication}

Not applicable.

\section{Competing interests}

There are no competing interests (political, religious, ideological, academic, intellectual, commercial or any other) to declare in relation to this manuscript.

\section{Author details}

${ }^{1}$ HealthPartners Institute, Bloomington, MN, USA. ${ }^{2}$ Minnesota Department of Health, 85 East 7th Place, P.O. Box 64882, St. Paul, MN 55164, USA.

${ }^{3}$ Minnesota Department of Human Services, St. Paul, MN, USA. ${ }^{4}$ University of California, La Jolla, San Diego, CA, USA. ${ }^{5}$ National Kidney Foundation, New York, NY, USA.

Received: 30 October 2019 Accepted: 13 October 2020

\section{Published online: 21 October 2020}

\section{References}

1. International Diabetes Foundation. IDF Diabetes Atlas. https://www.idf.org/ e-library/epidemiology-research/diabetes-atlas/134-idf-diabetes-atlas8thedition.html. Accessed 28 Oct 2019.

2. Haw JS, Galaviz Kl, Straus AN, et al. Long-term sustainability of diabetes prevention approaches: a systematic review and meta-analysis of randomized clinical trials. JAMA Intern Med. 2017;177(12):1808-17.

3. Galaviz KI, Weber MB, Straus A, Haw JS, Narayan KMV, Ali MK. Global diabetes prevention interventions: a systematic review and network metaanalysis of the real-world impact on incidence, weight, and glucose. Diabetes Care. 2018;41(7):1526-34.

4. Aziz Z, Absetz P, Oldroyd J, Pronk NP, Oldenburg B. A systematic review of real-world diabetes prevention programs: learnings from the last 15 years. Implementation Sci. 2015;10:172.

5. Nhim K, Gruss SM, Porterfield DS, et al. Using a RE-AIM framework to identify promising practices in National Diabetes Prevention Program implementation. Implementation Sci. 2019;14(1):81.

6. Barron E, Clark R, Hewings R, Smith J, Valabhji J. Progress of the healthier you: NHS diabetes prevention Programme: referrals, uptake and participant characteristics. Diabet Med. 2018;35(4):513-8.

7. O'Brien MJ, Whitaker RC, Yu D, Ackermann RT. The comparative efficacy of lifestyle intervention and metformin by educational attainment in the diabetes prevention program. Prev Med. 2015;77:125-30.

8. Jiang $L$, Huang $H$, Johnson $A$, et al. Socioeconomic disparities in weight and behavioral outcomes among American Indian and Alaska native participants of a translational lifestyle intervention project. Diabetes Care. 2015;38(11):2090-9.

9. Ely EK, Gruss SM, Luman ET, et al. A National Effort to prevent type 2 diabetes: participant-level evaluation of CDC's national diabetes prevention program. Diabetes Care. 2017.
10. Mudaliar U, Zabetian A, Goodman M, et al. Cardiometabolic risk factor changes observed in diabetes prevention programs in US settings: a systematic review and meta-analysis. PLoS Med. 2016;13(7):e1002095.

11. Menke A, Casagrande S, Geiss L, Cowie CC. Prevalence of and trends in diabetes among adults in the United States, 1988-2012. JAMA. 2015; 314(10):1021-9.

12. U.S. Department of Commerce Economics and Statistics Administration U.S. Census Bureau. Income and Poverty in the United States: 2016; Current Population Reports 2016; https://www.census.gov/content/dam/Census/ library/publications/2017/demo/P60-259.pdf. Accessed November 12, 2018.

13. Abdus S, Mistry KB, Selden TM. Racial and ethnic disparities in services and the patient protection and affordable care act. Am J Public Health. 2015; 105(Suppl 5):S668-75.

14. American Diabetes Association. Economic Costs of Diabetes in the U.S. in 2017. Diabetes Care. 2018;41(5):917-28.

15. Volpp KG, John LK, Troxel AB, Norton L, Fassbender J, Loewenstein G. Financial incentive-based approaches for weight loss: a randomized trial. JAMA. 2008;300(22):2631-7.

16. Halpern SD, French B, Small DS, et al. Randomized trial of four financial-incentive programs for smoking cessation. N Engl J Med. 2015; 372(22):2108-17.

17. John LK, Loewenstein G, Troxel AB, Norton L, Fassbender JE, Volpp KG. Financial incentives for extended weight loss: a randomized, controlled trial. J Gen Intern Med. 2011;26(6):621-6.

18. Kullgren JT, Troxel AB, Loewenstein $G$, et al. Individual- versus group-based financial incentives for weight loss: a randomized, controlled trial. Ann Intern Med. 2013;158(7):505-14.

19. Mitchell MS, Goodman JM, Alter DA, et al. Financial incentives for exercise adherence in adults: systematic review and meta-analysis. Am J Prev Med. 2013:45(5):658-67.

20. Giles EL, Robalino S, McColl E, Sniehotta FF, Adams J. The effectiveness of financial incentives for health behaviour change: systematic review and meta-analysis. PLoS One. 2014;9(3):e90347.

21. Haff N, Patel MS, Lim R, et al. The role of behavioral economic incentive design and demographic characteristics in financial incentive-based approaches to changing health behaviors: a meta-analysis. Am J Health Promot. 2015;29(5):314-23.

22. O'Donoghue T. M R. the economics of immediate gratification. J Behav Dec Making. 2000;13:233-50

23. Mantzari E, Vogt F, Shemilt I, Wei Y, Higgins JP, Marteau TM. Personal financial incentives for changing habitual health-related behaviors: a systematic review and meta-analysis. Prev Med. 2015;75:75-85.

24. Patel MS, Asch DA, Rosin R, et al. Individual versus team-based financial incentives to increase physical activity: a randomized, controlled trial. J Gen Intern Med. 2016;31(7):746-54.

25. Mattke S, Kapinos K, Caloyeras JP, et al. Workplace wellness programs: services offered, participation, and incentives. Rand Health Q. 2015;5(2):7.

26. John LK, Loewenstein G, Volpp KG. Empirical observations on longer-term use of incentives for weight loss. Prev Med. 2012;55(Suppl):S68-74.

27. Hamman RF, Wing RR, Edelstein SL, et al. Effect of weight loss with lifestyle intervention on risk of diabetes. Diabetes Care. 2006;29(9):2102-7.

28. Hoerger TJ, Perry R, Farrell K, Teixeira-Poit S. Can incentives improve Medicaid patient engagement and prevent chronic diseases? N C Med J. 2015;76(3):180-4.

29. VanEpps EM, Troxel AB, Villamil E, et al. Effect of process- and outcomebased financial incentives on weight loss among Prediabetic New York Medicaid patients: a randomized clinical trial. Am J Health Promot. 2019; 33(3):372-80

30. Desai J, Taylor G, Vazquez-Benitez G, et al. Financial incentives for diabetes prevention in a Medicaid population: study design and baseline characteristics. Contemp Clin Trials. 2017;53:1-10.

31. Center for Disease Control and Prevention. The 2012 CDC-Developed Diabetes Prevention Program Curriculum and Handouts: https://www.cdc. gov/diabetes/prevention/resources/curriculum.html. Accessed 28 Oct 2015.

32. Brokaw SM, Carpenedo D, Campbell P, Helgerson S, Harwell T. Do Financial incentives make a difference in outcomes for Medicaid members in the diabetes prevention program (DPP)? Paper presented at: ADA 76th scientific sessions 2016; New Orleans, LA.

33. Alva ML, Romaire M, Acquah J. Impact of financial incentives on diabetes prevention class attendance and program completion: evidence from Minnesota, Montana, and New York. Am J Health Promot. 2019;33(4):601-5. 
34. Jeffery RW. Financial incentives and weight control. Prev Med. 2012 55(Suppl):S61-7.

35. Jeffery RW, Kelly KM, Rothman AJ, Sherwood NE, Boutelle KN. The weight loss experience: a descriptive analysis. Ann Behavi Med. 2004;27(2):100-6.

36. Baumeister RF, Gailliot M, DeWall CN, Oaten M. Self-regulation and personality: how interventions increase regulatory success, and how depletion moderates the effects of traits on behavior. J Pers. 2006;74(6): 1773-801.

37. Patel MS, Asch DA, Rosin $R$, et al. Framing financial incentives to increase physical activity among overweight and obese adults: a randomized, controlled trial. Ann Intern Med. 2016;164(6):385-94.

38. Loewenstein G, Asch DA, Volpp KG. Behavioral economics holds potential to deliver better results for patients, insurers, and employers. Health Aff (Millwood). 2013;32(7):1244-50.

39. Sykes-Muskett BJ, Prestwich A, Lawton RJ, Armitage CJ. The utility of monetary contingency contracts for weight loss: a systematic review and meta-analysis. Health Psychol Rev. 2015;9(4):434-51.

40. Ackermann RT, Liss DT, Finch EA, et al. A randomized comparative effectiveness trial for preventing type 2 diabetes. Am J Public Health. 2015; 105(11):2328-34

41. Dunkley AJ, Bodicoat DH, Greaves CJ, et al. Diabetes prevention in the real world: effectiveness of pragmatic lifestyle interventions for the prevention of type 2 diabetes and of the impact of adherence to guideline recommendations: a systematic review and meta-analysis. Diabetes Care. 2014;37(4):922-33.

42. Gilmer T, O'Connor PJ, Schiff JS, et al. Cost-effectiveness of a communitybased diabetes prevention program with participation incentives for Medicaid beneficiaries. Health Serv Res. 2018;53(6):4704-24.

43. Ritchie ND, Gritz RM. New Medicare diabetes prevention coverage may limit beneficiary access and widen health disparities. Med Care. 2018; 56(11):908-11

44. Ritchie ND, Kaufmann P, Sauder KA. Comment on Ely et al. a National Effort to prevent type 2 diabetes: participant-level evaluation of CDC's National Diabetes Prevention Program. Diabetes care 2017;40:1331-1341. Diabetes Care. 2017:40(11):e161-2.

45. Lovasi GS, Hutson MA, Guerra M, Neckerman KM. Built environments and obesity in disadvantaged populations. Epidemiol Rev. 2009;31:7-20.

46. McGinnis P, Davis MM, Howk S, DeSordi M, Thomas M. Integrating primary care practices and community-based resources to manage obesity: a bridge-building toolkit for rural primary care practice transformation. Oregon Rural Practice-based Research Network. Oregon Health \& Science University.2014.

\section{Publisher's Note}

Springer Nature remains neutral with regard to jurisdictional claims in published maps and institutional affiliations.

Ready to submit your research? Choose BMC and benefit from:

- fast, convenient online submission

- thorough peer review by experienced researchers in your field

- rapid publication on acceptance

- support for research data, including large and complex data types

- gold Open Access which fosters wider collaboration and increased citations

- maximum visibility for your research: over $100 \mathrm{M}$ website views per year

At $\mathrm{BMC}$, research is always in progress.

Learn more biomedcentral.com/submissions 